\title{
Application of the modified similarity-based method for multi-criteria inventory classification
}

\author{
Bivash Mallick $^{a^{*}}$, Sourav Das ${ }^{\mathrm{a}}$, Bijan Sarkar $^{\mathrm{b}}$ and Santanu Das $^{\mathrm{c}}$
}

\begin{abstract}
${ }^{a}$ Department of Industrial Engineering and Management, Maulana Abul Kalam Azad University of Technology, West Bengal, India ${ }^{b}$ Department of Production Engineering, Jadavpur University, Kolkata, India ${ }^{c}$ Department of Mechanical Engineering, Kalyani Government Engineering College, West Bengal, India

\begin{tabular}{l}
\hline C H R O N I C L E \\
\hline Article history: \\
Received November 26, 2018 \\
Received in revised format: \\
May 10, 2019 \\
Accepted May 9, 2019 \\
Available online \\
May 10, 2019 \\
\hline Keywords: \\
ABC classification \\
Multi-criteria decision making \\
Multi-criteria inventory \\
classification \\
Modified similarity \\
AHP \\
TOPSIS
\end{tabular}
A B S T R A C T

In the era of digital manufacturing and highly competitive environment, it is desirable to deliver the right item, right quantity at right time at minimal cost. Under this volatile market environment, the inventory should be readily available at the manufacturing level at the lowest possible cost. Many industries have been conventionally employing traditional ABC analyses based on a single criterion of annual consumption cost for classification of inventory items in spite of other criteria such as unit cost, consumption rate, average inventory cost that may be important in inventory classification. To address such problems, incorporation of Multi-criteria decision making (MCDM) methods is considered an advantage. The present article focuses on a new approach to categorize inventory items using Modified similarity-based method. The proposed method is applied to the inventory data of raw materials from a renowned conveyor belt manufacturing company of West Bengal, India. By using Modified similarity-based method, the items are classified in A, B and C categories. Results obtained from the said method using R program are compared with those of well recognized TOPSIS and AHP methodologies to validate the application of this method for inventory classification.
\end{abstract}

\section{Introduction}

Inventories are defined as idle resources of any kind having economic values. Appropriate inventory control is necessary because both its surplus and deficit efficiency largely affects the cost of its operation. Thus inventory control is essential to determine the item(s) to indent (i.e., to order) along with with its quantity, time to indent and the optimum stock to maintain so that purchase and storage costs are minimized (Mallick et al., 2012). Hence, the management of an organization put substantial attention on the planning and control of inventory.

Although $\mathrm{ABC}$ analysis can be employed to almost all aspects of materials management, traditional $\mathrm{ABC}$ analysis considers the cost of annual consumption of inventory items. Consumption costs are arranged in descending order. The cumulative percentage is calculated based on cumulative consumption cost, and correspondingly, A, B and C classifications are made. The choice of breakpoint percentages to classify the inventories by the management can be done on the basis of a number of effectively managed items under each category (Flores et al., 1992).

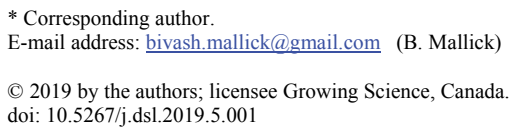


A number of researchers have questioned the focus on the consumption value as a single criterion. Cohen and Ernst (1988) opined that many other criteria may be significant to evaluate the importance of inventory items. In these cases, multiple criteria decision-making methods are helpful.

Keeping the above background in view, the objective of this paper based on case-study is to classify inventory items using the Modified similarity-based method with R-programming. Results obtained from this approach are compared with that of TOPSIS model and the AHP (Analytic Hierarchy Process) separately to validate this method.

\section{Review of the literature}

In the past, some investigators have worked on multi-criteria inventory classification (MCIC). This approach was brought in by Flores and Whybark $(1986,1987)$. Their approach became increasingly complicated if more than two criteria were considered. Flores et al. (1992) applied the AHP for MCIC, while various products of a company were classified using a fuzzy method by Puente et al. (2002). Their study reported how fuzzy set theory allows uncertainty to be incorporated into the classification model which also reflects the business reality of the market accurately. Guvenir and Erel (1998) used the Genetic Algorithm (GA) fruitfully to find the solution of MCIC problem naming the method GAMIC. On the other hand, Braglia et al. (2004) used the AHP for identification of the outstanding control strategy to manage the inventory of spare parts. A weighted linear optimization model for MCIC was introduced by Ramanathan (2006). Data Envelopment Analysis (DEA) was used for obtaining the Performance score for each item. Limitation of this model was detected to be the possibility of misclassifying some items. Zhou and Fan (2007) rectified this problem by incorporating balancing features for MCIC by using the highest and lowest favorable score for each item. In another work, Bhattacharya et al. (2007) utilized the concept of the TOPSIS model for ABC classification. Cakir and Canbolat (2008) proposed an MCIC by integrating fuzzy logic, when demand, lead time, payment terms, unit cost, and substitutability were taken for classifying inventory components using fuzzy AHP by Çebi et al. (2010). A modified DEA-like model was applied by Torabi et al. (2012) for ABC classification considering both the quantitative and qualitative criteria, while Kabir and Hasin (2013) developed an MCIC model by integrating Fuzzy-AHP and Neural Networks. Soylu and Akyol (2014) suggested an MCIC in terms of reference items into each class by taking preferences of the decision maker. A method known as EDAS (Evaluation based on Distance from Average Solution) was introduced by Ghorabaee et al. (2015) for solving some MCIC problems to find stability of the proposed method, whereas Liu et al. (2016) made a new classification approach using an outranking model that required consideration of non-compensation in ABC analysis. Mallick et al. (2017) integrated Graph Theory (GT) and the AHP as a decision analysis tool for MCIC. Mallick et al. (2016) also presented a multi-criteria inventory classification (MCIC) system by MOORA (Multi-Objective Optimization on the basis of Ratio Analysis) for hospital inventory management.

\section{The proposed methodology}

The modified similarity-based method used in this study is adapted from the TOPSIS methodology, which uses the notion of an ideal solution to compare a pair of alternatives. The lowest and the highest similarity to the negative and positive ideal solutions respectively are identified to be the most preferred alternative.

The modified similarity-based method has been applied by a number of researchers to solve several problems. This method has an added advantage of ranking alternatives for deciphering discrete multicriteria issues (Deng, 2007), ranking banks (Safari et al., 2013), personnel selection (Chaghooshi et al., 2014), ranking countries with respect to human development index (Safari \& Ebrahimi, 2014), ranking of organizations with regard to the measure taken for corporate governance (Moradi \& Ebrahimi, 2014), multi-objective optimization in drilling operation (Sonkar et al., 2014), cutting fluid selection (Prasad \& Chakraborty, 2018) etc. 
The study shows the application practicability of the modified similarity method towards Multi-Criteria Inventory Classification and related decision making in real time manufacturing atmosphere. The proposed methodology pursues steps listed below following Rao (2007), Safari et al. (2014) and Prasada et al. (2018)

Step 1: To identify the inventory attributes or criterion for the decision matrix.

Step 2: To generate the decision matrix based on the raw inventory data after suitable normalization.

A decision matrix can be represented as shown in Eq. (1). This reflects the performance of different alternatives related to varying attributes.

$$
D=\left[x_{i j}\right]_{i=1, \ldots, m, j=1, \ldots, n}
$$

when,

$\mathrm{x}_{\mathrm{ij}}$ : Measure of the performance of the $\mathrm{i}^{\text {th }}$ alternative over $\mathrm{j}^{\mathrm{it}}$ criteria

m: Number of alternatives

$\mathrm{n}$ : Number of criteria Information stored in a decision matrix.

Step 3: To construct the relative importance matrix

A relative importance matrix (Saaty, 1986, 1990) (Eq. 2) is the pair-wise comparison matrix made using the values taken from the 9-point scale (from 1 to 9) as proposed by (Saaty, 1980, 1994). If there are $\mathrm{N}$ numbers of criteria, the pair-wise comparison of the $i^{\text {th }}$ criterion with respect to the $j^{\text {th }}$ one gives rise to a square matrix. In this, $a_{i j}=1$ when $i=j$ and $a_{j i}=1 / a_{i j} . a_{i j}$ is the comparative importance of $i^{\text {th }}$ criterion with respect to the $\mathrm{j}^{\text {th }}$ one). The AHP using geometric mean method is employed (Rao, 2007) here for calculating weighting vector in Step 4 of the considered criteria:

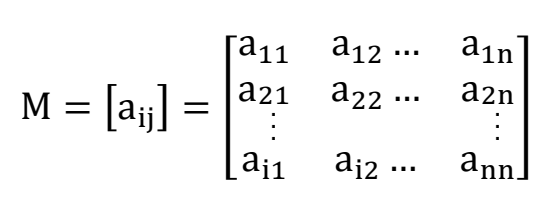

Step 4: To determine the weighting vector using Eq. (3).

$$
\mathrm{W}=\left(\mathrm{w}_{1}, \mathrm{w}_{2}, \ldots, \mathrm{w}_{\mathrm{m}}\right)
$$

Step 5: Normalized matrix is made using Eq. (4).

$$
\mathrm{X}^{\prime}=\left[\begin{array}{cccc}
\mathrm{x}_{11}^{\prime} & \mathrm{x}_{12}^{\prime} & \cdots & \mathrm{x}_{1 \mathrm{~m}}^{\prime} \\
\mathrm{x}_{21}^{\prime} & \mathrm{x}_{22}^{\prime} & \cdots & \mathrm{x}_{2 \mathrm{~m}}^{\prime} \\
\vdots & \vdots & \ddots & \vdots \\
\mathrm{x}_{\mathrm{n} 1}^{\prime} & \mathrm{x}_{\mathrm{n} 2}^{\prime} & \cdots & \mathrm{x}_{\mathrm{nm}}^{\prime}
\end{array}\right] ; \mathrm{x}_{\mathrm{ij}}^{\prime}=\frac{\mathrm{x}_{\mathrm{ij}}}{\sqrt{\sum_{\mathrm{k}=1}^{\mathrm{n}} \mathrm{x}_{\mathrm{kj}}}}
$$

where, $\mathrm{x}_{\mathrm{ij}}$ is the normalized performance of $\mathrm{i}^{\text {th }}$ alternative related to $\mathrm{j}^{\mathrm{it}}$ criteria and it is a dimensionless quantity lying within the interval $[0,1]$.

Step 6: To compute performance matrix as given in Eq. (5).

$$
\mathrm{Y}=\left[\begin{array}{cccc}
\mathrm{w}_{1} \mathrm{x}_{11}^{\prime} & \mathrm{w}_{2} \mathrm{x}_{12}^{\prime} & \ldots & \mathrm{w}_{\mathrm{m}} \mathrm{x}_{1 \mathrm{~m}}^{\prime} \\
\mathrm{w}_{1} \mathrm{x}_{21}^{\prime} & \mathrm{w}_{2} \mathrm{x}_{22}^{\prime} & \ldots & \mathrm{w}_{\mathrm{m}} \mathrm{x}_{2 \mathrm{~m}}^{\prime} \\
\vdots & \vdots & \ddots & \vdots \\
\mathrm{w}_{1} \mathrm{x}_{\mathrm{n} 1}^{\prime} & \mathrm{w}_{2} \mathrm{x}_{\mathrm{n} 2}^{\prime} & \ldots & \mathrm{w}_{\mathrm{m}} \mathrm{x}_{\mathrm{nm}}^{\prime}
\end{array}\right]=\left[\begin{array}{cccc}
\mathrm{y}_{11} & \mathrm{y}_{12} & \ldots & \mathrm{y}_{1 \mathrm{~m}} \\
\mathrm{y}_{21} & \mathrm{y}_{22} & \ldots & \mathrm{y}_{2 \mathrm{~m}} \\
\vdots & \vdots & \ddots & \vdots \\
\mathrm{y}_{\mathrm{n} 1} & \mathrm{y}_{\mathrm{n} 2} & \ldots & \mathrm{y}_{\mathrm{nm}}
\end{array}\right]
$$


Step 7: To find out positive and negative ideal solutions from Eq. (6) and Eq. (7).

$\mathrm{A}^{+}=\left(\mathrm{y}_{1}^{+}, \mathrm{y}_{2}^{+}, \ldots, \mathrm{y}_{\mathrm{m}}^{+}\right)$

$\mathrm{A}^{-}=\left(\mathrm{y}_{1}^{-}, \mathrm{y}_{2}^{-}, \ldots, \mathrm{y}_{\mathrm{m}}^{-}\right)^{\prime}$

where $\left\{\begin{array}{l}y_{j}^{+}=\max _{i=1,2, \ldots, n} y_{i j} \\ y_{j}^{-}=\min _{i=1,2, \ldots, n} y_{i j}\end{array}\right.$

Step 8: Calculate of the degree of conflict between each alternative to obtain positive and negative ideal solutions using Eq. (8) and Eq. (9).

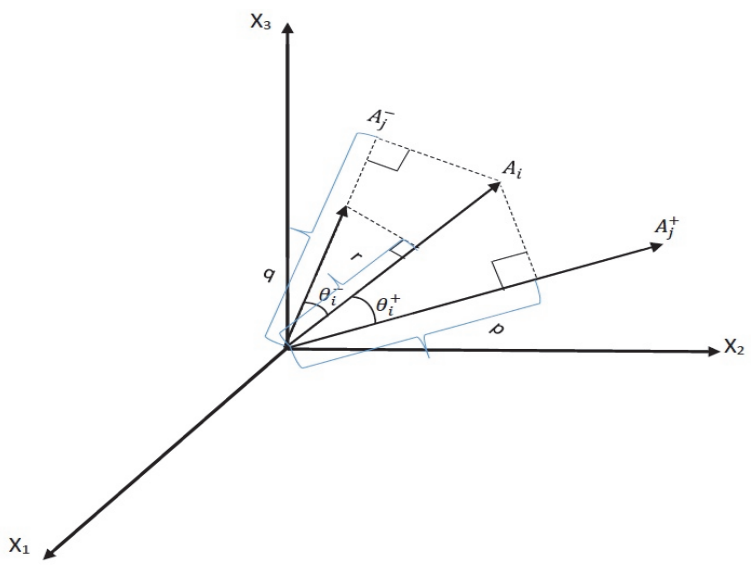

Fig. 1. The degree of conflict between alternatives and $\mathrm{Ai}$

$$
\begin{aligned}
& \cos \theta_{i}^{+}=\frac{\sum_{j=1}^{m} y_{i j} y_{j}^{+}}{\sqrt{\sum_{j=1}^{m} y_{i j}^{2}} \times \sqrt{\sum_{j=1}^{m}\left(y_{j}^{+}\right)^{2}}} \\
& \cos \theta_{i}^{+}=\frac{\sum_{j=1}^{m} y_{i j} y_{j}^{+}}{\sqrt{\sum_{j=1}^{m} y_{i j}^{2}} \times \sqrt{\sum_{j=1}^{m}\left(y_{j}^{+}\right)^{2}}}
\end{aligned}
$$

Step 9: To calculate the degree of similarity between alternatives and the positive and negative-ideal solution by Eq. (10) and Eq. (11)

$$
\begin{aligned}
& \mathrm{S}_{\mathrm{i}}^{+}=\frac{\left|\mathrm{C}_{\mathrm{i}}^{+}\right|}{\left|\mathrm{A}^{+}\right|}=\frac{\cos \theta_{\mathrm{i}}^{+} \times\left|\mathrm{A}_{\mathrm{i}}\right|}{\left|\mathrm{A}^{+}\right|}=\frac{\cos \theta_{\mathrm{i}}^{+} \times \sqrt{\sum_{\mathrm{j}=1}^{\mathrm{m}} \mathrm{y}_{\mathrm{ij}}^{2}}}{\sqrt{\sum_{\mathrm{j}=1}^{\mathrm{m}}\left(\mathrm{y}_{\mathrm{j}}^{+}\right)^{2}}} \\
& \mathrm{~S}_{\mathrm{i}}^{-}=\frac{\left|\mathrm{A}^{-}\right|}{\left|\mathrm{C}_{\mathrm{i}}^{-}\right|}=\frac{\left|\mathrm{A}^{-}\right|}{\cos \theta_{\mathrm{i}}^{-} \times\left|\mathrm{A}_{\mathrm{i}}\right|}=\frac{\sqrt{\sum_{\mathrm{j}=1}^{\mathrm{m}}\left(\mathrm{y}_{\mathrm{j}}^{-}\right)^{2}}}{\cos \theta_{\mathrm{i}}^{-} \times \sqrt{\sum_{\mathrm{j}=1}^{\mathrm{m}} \mathrm{y}_{\mathrm{ij}}^{2}}}
\end{aligned}
$$


Step 10: To calculate the overall performance index for each alternative across all criteria by Eq. (12).

$$
\mathrm{P}_{\mathrm{i}}=\frac{\mathrm{S}_{\mathrm{i}}^{+}}{\mathrm{S}_{\mathrm{i}}^{+}+\mathrm{S}_{\mathrm{i}}^{-}} \text {. }
$$

Step 11:In this step, all inventory items are ranked according to their overall performance index value arranged in descending order.

Fig. 2 indicates the procedure of the modified similarity-based method applied classifying inventory items as $\mathrm{A}, \mathrm{B}$ or $\mathrm{C}$.

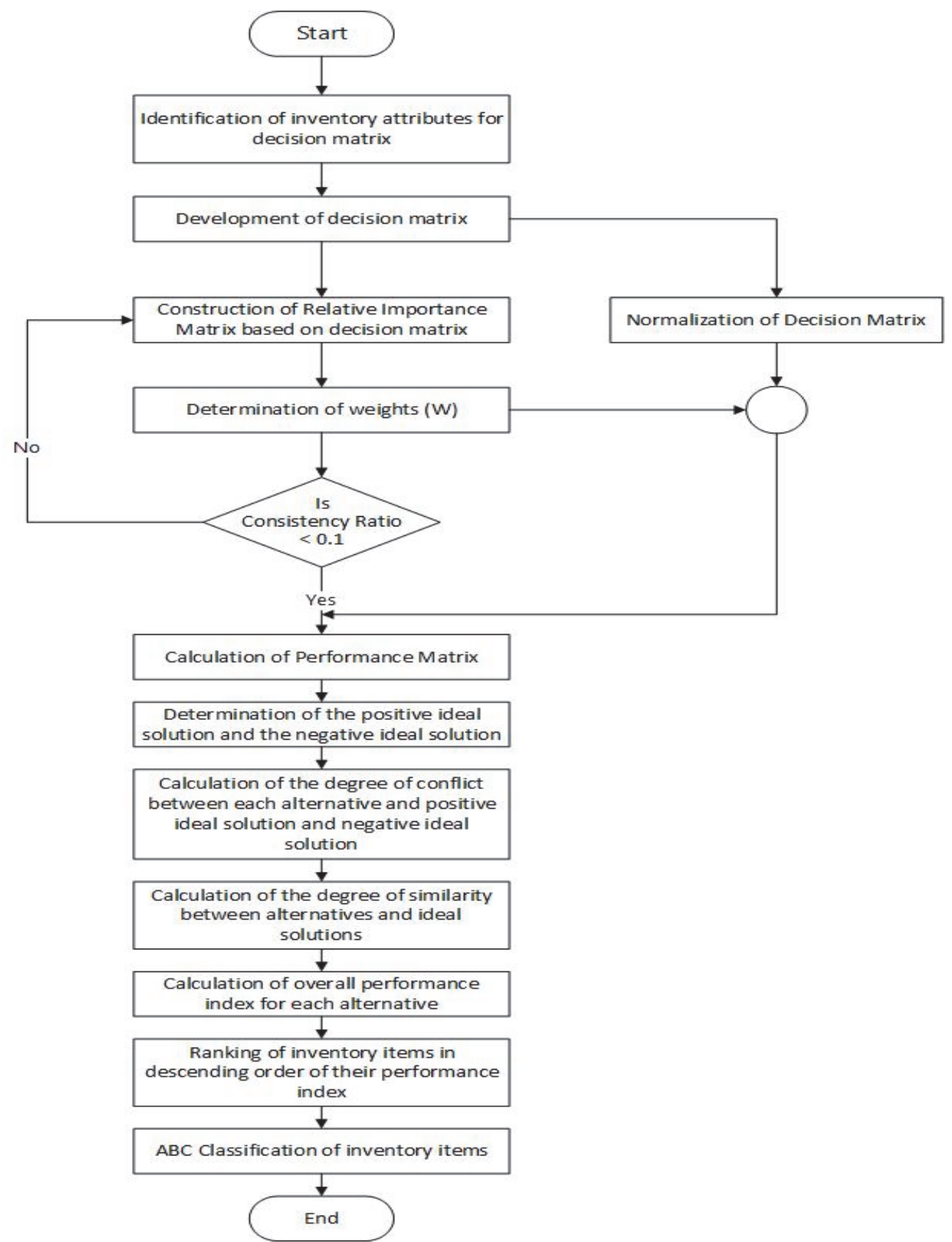

Fig. 2. Procedure for $A B C$ classification by the modified similarity-based method 


\section{Case study}

The paper envisaged to test the modified similarity-based method using inventory data of raw materials from a well-known conveyor belt manufacturing company, located in the state of West Bengal, India. To acquire the preliminary knowledge about the company, feedback through questionnaire was collected. Upon interpretation of the data thus obtained, the inventory practice prevalent in that company was found to be inadequate as reported in (Mallick et al., 2012). In the context of total inventory, it has been found from the analyses of organizational data that Raw Materials (RWM) occupies the major share. RWM are further sub-grouped into seven categories. Of these, almost $70 \%$ of RWM inventory is shared by four categories. In the first of inventory analysis, a monthly variation of Total RWM Inventory Cost was estimated and presented in Fig. 3. Next, a monthly variation of total inventory for four categories stated for the paper exhibited in Fig. 4, was prepared. The similar pattern of curves in Fig. 3 and Fig. 4 strengthen the assumption that four categories of materials have been appropriately selected for multi-criteria inventory classification.

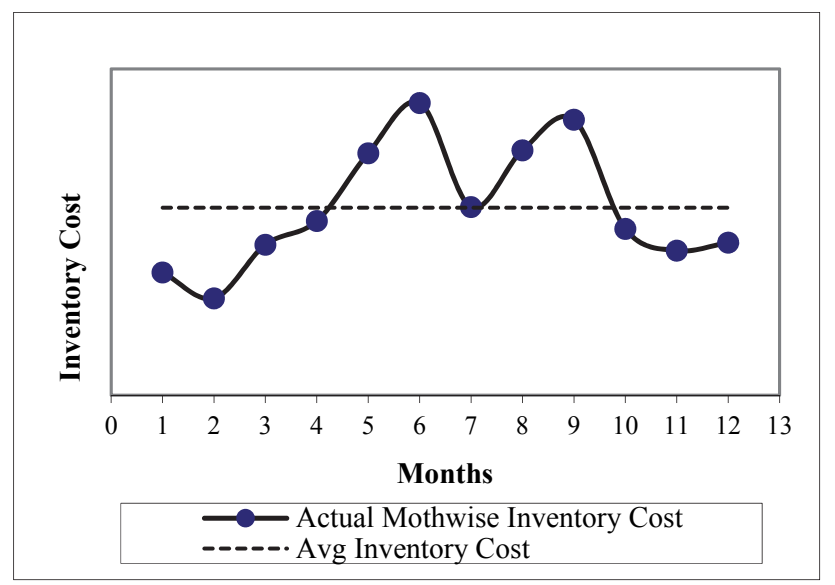

Fig. 3. Monthly variation of Total RWM Inventory Cost (Mallick et al., 2012)

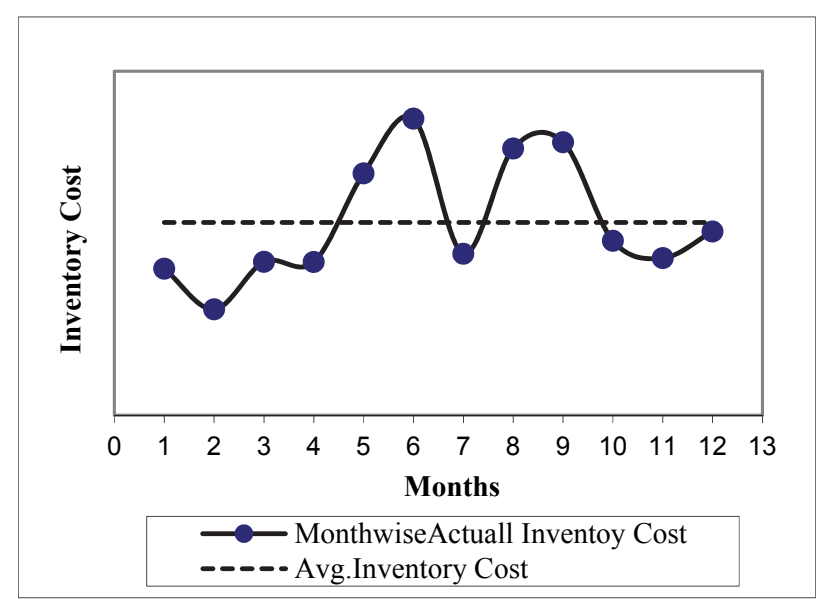

Fig. 4. Monthly variation of Total Inventory Cost for 4 categories stated for the paper (Mallick et al., 2012)

In this paper, analyses using the modified similarity-based method of the above-mentioned four categories of RWM of 90 items are presented. Items are codified as RWM01, RWM02 .... to maintain the confidentiality of the company. The four criteria - Unit Cost (INR), Annual Consumption Cost 
(INR), Annual Consumption Rate (No. of issues/year), and Average Inventory Cost (INR) were decided as very significant for classification of inventory items by these authors and management personnel of the concerned company. The modified similarity-based method has been applied for the ABC analysis to identify those items having a major financial impact with high demand in the shop floor.

The procedure of applying the methodology for the multi-criteria inventory classification, given in Section 3, is described below:

1. With all the values related to the chosen criteria for each item considered in this case study, a decision matrix is formulated as shown in Appendix A.

2. The Relative Importance Relation Matrix (table 1) is made following the expert opinion of the said company. The AHP using geometric mean method is employed (Rao, 2007) here for computing priority weights of criteria. The weight $\left(\mathrm{w}_{\mathrm{i}}\right)$ of each criteria is calculated as: unit cost: 0.105 ; annual consumption cost: 0.395 ; consumption rate: 0.314 ; and average inventory cost: 0.187 . The last row of Appendix A contains these weights.

Table 1

Relative Importance Relation Matrix

\begin{tabular}{|c|c|c|c|c|}
\hline & Unit cost & $\begin{array}{c}\text { Annual Consumption } \\
\text { Cost }\end{array}$ & Yearly Issue & $\begin{array}{c}\text { Annual } \\
\text { Inventory Cost }\end{array}$ \\
\hline Unit cost & 1 & $1 / 5$ & $1 / 2$ & $1 / 2$ \\
\hline Annual Consumption Cost & 5 & 1 & 1 & 2 \\
\hline Yearly Issue & 2 & 1 & 1 & 2 \\
\hline Annual Inventory Cost & 2 & $1 / 2$ & $1 / 2$ & 1 \\
\hline
\end{tabular}

3. A simulation model using spreadsheets and R program (Appendix B) is created to determine the effect of using modified similarity-based method for inventory classification and a comparison of the proposed modified similarity-based ABC classification with that of the well documented TOPSIS (Bhattacharya et al., 2007; Hwang \& Yoon, 1981) and AHP (Rao, 2007; Saaty, 1980, 1994) classification techniques.

A comparison amongst the outcomes of the three methodologies in the form of rankings of the alternatives in descending order of their performance scores is presented in Appendix C.

Table 2 presents that $75 \%$ of the total annual consumption cost is considered as the single criterion attributable to $12 \%$ of the total number of items under category A as per traditional ABC analysis; $4 \%$ is from more than $59 \%$ of total items under category $\mathrm{C}$ and $21 \%$ is from nearly $29 \%$ of the overall items under category B.

For fruitful comparison, all the three MCDM methods (Modified similarity-based method, TOPSIS and AHP method) have also been considered utilizing the same allocation pattern of the traditional ABC classification of 11, 25 and 54 items under class A, B, and C respectively. Comparative analysis of annual consumption cost percentage of $\mathrm{A}, \mathrm{B}$ and $\mathrm{C}$ type of items obtained from all $3 \mathrm{MCDM}$ types of $\mathrm{ABC}$ analyses is depicted in Table 2.

Table 2 illustrates that $71.35 \%$ of the annual consumption cost by using Modified similarity-based method is responsible for ' $A$ ' type of items as compared to $69.94 \%$ by TOPSIS and AHP method. For ' $\mathrm{B}$ ' type of items, $12.00 \%$ is accounted for by using Modified similarity-based method, $12.78 \%$ by TOPSIS and $12.60 \%$ by AHP method. For ' $\mathrm{C}$ ' type of items, $16.65 \%$ is for Modified similarity-based method, $17.28 \%$ for TOPSIS and $17.46 \%$ for the AHP. Therefore, it can be stated that desirable inventory control is possible by managing 'A' group items only. 
Table 2

A comparison of annual consumption cost percentage of class A, B and C type of items for Traditional ABC classification Modified Similarity-Based Method, TOPSIS, and AHP methodologies

\begin{tabular}{ccccccc}
\hline $\begin{array}{c}\text { Class } \\
\text { of }\end{array}$ & $\begin{array}{c}\text { No. of } \\
\text { items }\end{array}$ & $\begin{array}{c}\% \text { of } \\
\text { Items }\end{array}$ & \multicolumn{2}{c}{$\begin{array}{c}\text { Traditional ABC } \\
\text { classification based on }\end{array}$} & \multicolumn{2}{c}{ Annual Consumption Cost } \\
items
\end{tabular}

\section{Comparative analysis}

For comparing the relative performance of modified similarity-based method with that of TOPSIS and AHP while solving this multi-criteria inventory classification problem, the following tests are performed.

(a) Scatterplot Matrix

(b) Kendall's coefficient of concordance,

(c) Spearman's rank correlation coefficient,

First, ranks of items obtained by using Modified similarity-based method, TOPSIS, and AHP are plotted in a scatter plot matrix (Cleveland, 1993; Emerson et al., 2013) (Fig. 5). Each panel of the scatter plot matrix in Fig. 5 represents the scatter plot of one variable against the other revealing ranking similarity amongst them.
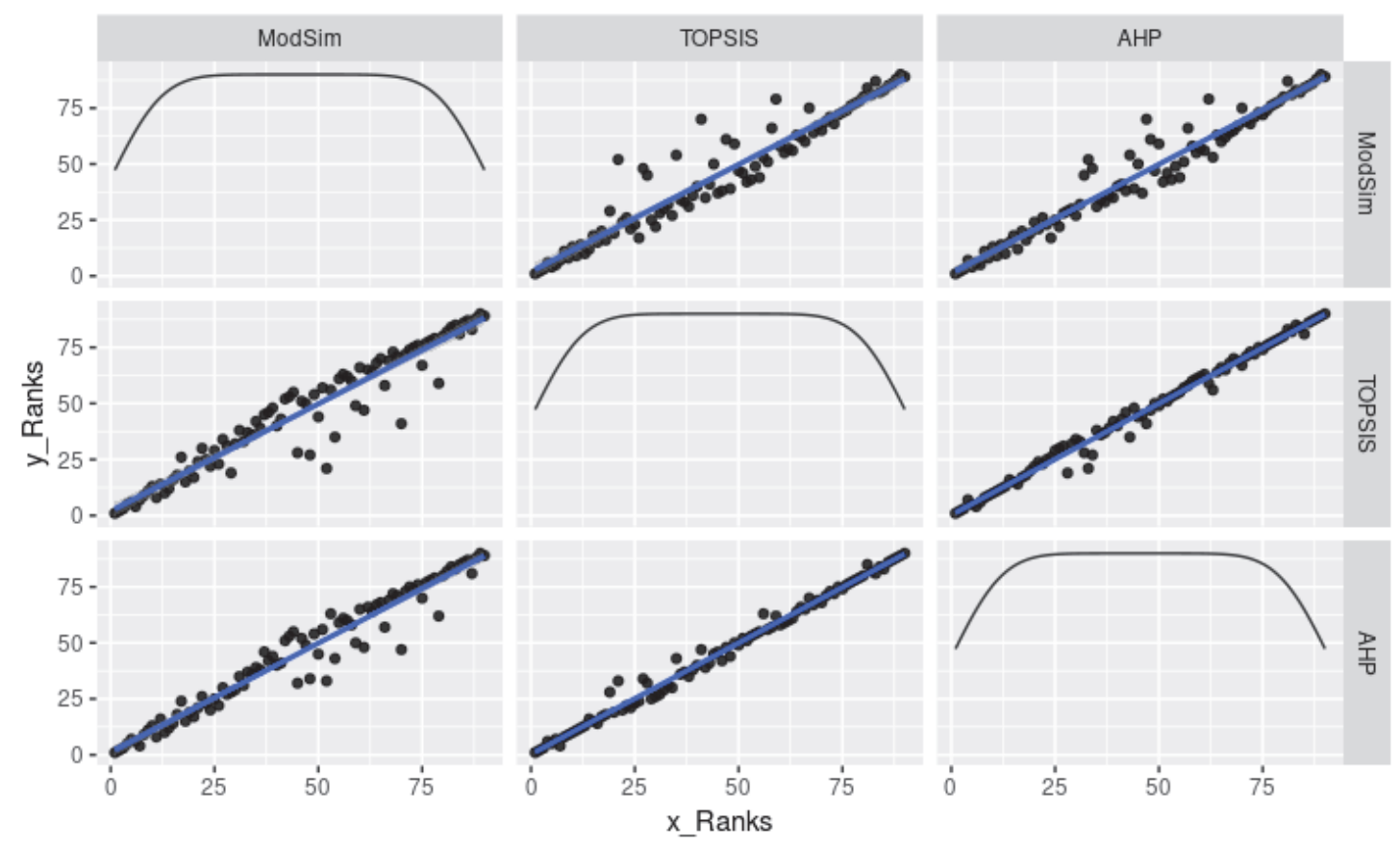

Fig. 5. A scatter plot matrix for ranks of items obtained by using modified similarity method, TOPSIS, and AHP

Overall ranking agreement among the methods considered is next determined using Kendall's coefficient of concordance (z) value (range: $0-1$ ). Value of 1 represents a perfect match (Athawale \& Chakraborty, 2011; Hajkowicz \& Higgins, 2008). For this multi-criteria inventory classification problem, the $\mathrm{z}$ value of 0.98347 is evaluated that is quite close to 1 . It indicates close conformity between these MCDM methods. 
Spearman's rank correlation coefficient $\left(r_{s}\right)$ is utilized (Athawale \& Chakraborty, 2011; Sheskin, 2004) in the third test to compute the similarity between two sets of rankings. +1 value of $r_{s}$ indicates a perfect match between two rank orders, and in this work, $r_{s}$ values range from 0.96 to 0.99 (Table 3 ).

Table 3

Spearman's rank correlation coefficient

\begin{tabular}{lcc}
\multicolumn{1}{c}{ Method } & TOPSIS & AHP \\
\hline Modified Similarity & 0.96 & 0.97 \\
TOPSIS & & 0.99 \\
\hline
\end{tabular}

\section{Conclusions}

In the present investigation, the modified similarity-based method is used for MCIC. These authors could not find this kind of methodology to have been used earlier to classify inventory items. An inventory management system of raw materials for 90 items of a renowned conveyor belt manufacturing company has been considered for this work. Results acquired using the proposed method are compared with those of TOPSIS and AHP for validation. Following are the inferences observed:

- The outcome of this work is that application of multi-criteria decision-making method i.e. modified similarity-based method to Inventory management, enables one to control $71.35 \%$ of the annual consumption cost by controlling only ' $A$ ' type of items (12\%), but which could be accounted for $69.94 \%$ in TOPSIS as well as AHP method. Therefore, it is stated that for any organization, inventory cost-control as well as multi-criteria decision making both can be attained by applying a modified similarity-based method from a materials management point of view.

- The modified similarity-based method may be recommended for practical use in the decisionmaking method for classification of multi-criteria inventory items.

The present work considers the decision taken under certainty, which is otherwise often highly uncertain and risky for the decision-makers. Therefore, the applicability of this method may be elevated by introducing fuzzy set theory for consideration of uncertainty and vagueness in attribute values. In order to use modified similarity-based method advantageously for solving the classification of inventory items with imprecise and vague data, the fuzzy modified similarity-based method may be proposed for future study.

\section{References}

Athawale, V. M., \& Chakraborty, S. (2011). A comparative study on the ranking performance of some multi-criteria decision-making methods for industrial robot selection. International Journal of Industrial Engineering Computations, 2(4), 819-830.

Bhattacharya, A., Sarkar, B., \& Mukherjee, S. K. (2007). Distance-based consensus method for ABC analysis. International Journal of Production Research, 45(15), 3405-3420.

Braglia, M., Grassi, A., \& Montanari, R. (2004). Multi-attribute classification method for spare parts inventory management. Journal of Quality in Maintenance Engineering, 10(1), 55-65.

Cakir, O., \& Canbolat, M. S. (2008). A web-based decision support system for multi-criteria inventory classification using fuzzy AHP methodology. Expert Systems with Applications, 35(3), 1367-1378.

Çebi, F., Kahraman, C., \& Bolat, B. (2010). A multiattribute ABC classification model using fuzzy AHP. In The 40th International Conference on Computers \& Industrial Engineering (pp. 1-6).

Chaghooshi, A. J., Janatifar, H., \& Dehghan, M. (2014). An application of AHP and similarity-based approach to personnel selection. International Journal of Business Management and Economics, 
$1(1), 24-32$.

Cleveland, W. S. (1993). Visualizing data. Hobart Press.

Cohen, M. A., \& Ernst, R. (1988). Multi-item classification and generic inventory stock control policies. Production and Inventory Management Journal, 29(3), 6-8.

Deng, H. (2007). A similarity-Based Approach to Ranking Multicriteria Alternatives. In International Conference on Intelligent Computing, Lecture Notes in Artificial Intelligence,4682 (pp. 253-262).

Emerson, J. W., Green, W. A., Schloerke, B., Crowley, J., Cook, D., Hofmann, H., \& Wickham, H. (2013). The generalized pairs plot. Journal of Computational and Graphical Statistics, 22(1), 79 91.

Flores, B. E., Olson, D. L., \& Dorai, V. K. (1992). Management of multicriteria inventory classification. Mathematical and Computer Modelling, 16(12), 71-82.

Flores, B. E., \& Whybark, D. C. (1986). Multiple Criteria ABC Analysis. International Journal of Operations \& Production Management, 6(3), 38-46.

Flores, B. E., \& Whybark, D. C. (1987). Implementing Multiple Criteria ABC Analysis. Journal of Operations Management, 7(1-2), 79-85.

Ghorabaee, M. K., Zavadskas, E. K., Olfat, L., \& Turskis, Z. (2015). Multi-Criteria Inventory Classification Using a New Method of Evaluation Based on Distance from Average Solution ( EDAS ). Informatica, 26(3), 435-451.

Guvenir, H. ., \& Erel, E. (1998). Multicriteria inventory classification using a genetic algorithm. European Journal of Operational Research, 105(1), 29-37.

Hajkowicz, S., \& Higgins, A. (2008). A comparison of multiple criteria analysis techniques for water resource management. European Journal of Operational Research, 184(1), 255-265.

Hwang, C.-L., \& Yoon, K. (1981). Methods for Multiple Attribute Decision Making. In M. Beckmann \& H. P. Kunzi (Eds.), Lecture Notes in Economics and Mathematical Systems (pp. 58-191). Springer-Verlag Berlin.

Kabir, G., \& Hasin, M. A. A. (2013). Multi-criteria inventory classification through the integration of fuzzy analytic hierarchy process and artificial neural network. International Journal and Systems Engineering, 14(1), 74-103.

Liu, J., Liao, X., Zhao, W., \& Yang, N. (2016). A classification approach based on the outranking model for multiple criteria ABC analysis. Omega, 61(June), 19-34.

Mallick, B., Dutta, O. N., \& Das, S. (2012). A case study on inventory management using selective control techniques. Journal of The Association of Engineers, India, 82(1 \& 2), 10-24.

Mallick, B., Sarkar, B., \& Das, S. (2017a). A Unified Decision Framework for Inventory Classification through Graph Theory. International Journal of the Analytic Hierarchy Process, 9(2), 183-198.

Mallick, B., Sarkar, B., \& Das, S. (2017b). Application of the MOORA Method for Multi-Criteria Inventory Classification. Indian Science Cruiser, 31(6), 15-21.

Moradi, M., \& Ebrahimi, E. (2014). Applying Fuzzy AHP and Similarity-Based Approach for Economic Evaluating Companies Based on Corporate Governance Measures. Global Journal of Management Studies and Researches, 1(1), 10-20.

Prasad, K., \& Chakraborty, S. (2018). Application of the modified similarity-based method for cutting fluid selection. Decision Science Letters, 7(3), 273-286.

Ramanathan, R. (2006). ABC inventory classification with multiple-criteria using weighted linear optimization. Computers and Operations Research, 33(3), 695-700.

Rao, R. V. (2007). Decision Making in the Manufacturing Environment Using Graph theory and Fuzzy Multiple Attribute Decision Making Methods. Springer Verlag, London.

Saaty, T. L. (1980). The Analytic Hierarchy Process. McGraw-Hill Inc. https://doi.org/0070543712

Saaty, T. L. (1986). Exploring optimization through hierarchies and ratio scales. Socio-Economic Planning Sciences, 20(6), 355-360.

Saaty, T. L. (1990). How to make a decision: The analytic hierarchy process. European Journal of Operational Research, 48(1), 9-26.

Saaty, T. L. (1994). How to Make a Decision: The Analytic Hierarchy Process. Interfaces, 24(6), 1943. 
Safari, H., \& Ebrahimi, E. (2014). Using modified similarity multiple criteria decision-making technique to rank countries in terms of human development index. Journal of Industrial Engineering and Management, 7(1), 254-275.

Safari, H., Khanmohammadi, E., Hafezamini, A., \& Ahangari, S. S. (2013). A New Technique for Multi-Criteria Decision Making Based on Modified Similarity Method. Middle-East Journal of Scientific Research, 14(5), 712-719.

Sheskin, D. J. (2004). Handbook of parametric and nonparametric statistical procedures. Chapman and Hall/CRC.

Sonkar, V., Abhishek, K., Datta, S., \& Mahapatra, S. S. (2014). Multi-objective Optimization in Drilling of GFRP Composites: A Degree of Similarity Approach. Procedia Materials Science, 6, 538-543.

Soylu, B., \& Akyol, B. (2014). Computers \& Industrial Engineering Multi-criteria inventory classification with reference items q. Computers \& Industrial Engineering, 69(March), 12-20.

Torabi, S. A., Hatefi, S. M., \& Pay, B. S. (2012). ABC inventory classification in the presence of both quantitative and qualitative criteria. Computers \& Industrial Engineering, 63(2), 530-537.

Zhou, P., \& Fan, L. (2007). Short Communication A note on multi-criteria ABC inventory classification using weighted linear optimization. European Journal of Operational Research, 182(3), 1488-1491.

\section{Appendix A}

Decision Matrix for multi-criteria inventory classification problem.

\begin{tabular}{|c|c|c|c|c|}
\hline Code No & Rate (INR) & Annual Consumption Cost (INR) & $\begin{array}{c}\text { Yearly Issue } \\
\text { (No. of issues/year) }\end{array}$ & Avg Inventory cost(INR) \\
\hline RWM01 & 104189.00 & 21551494.65 & 39 & 738786.80 \\
\hline RWM02 & 92826.00 & 1871372.16 & 9 & 585292.82 \\
\hline RWM03 & 95508.00 & 196493383.80 & 352 & 9166366.90 \\
\hline RWM04 & 99374.00 & 15229065.50 & 80 & 914043.29 \\
\hline RWM05 & 22446.00 & 48258.90 & 4 & 26569.44 \\
\hline RWM06 & 86159.00 & 39519840.92 & 195 & 2006615.65 \\
\hline RWM07 & 79946.00 & 51391687.18 & 204 & 36332913.16 \\
\hline RWM08 & 90559.00 & 45609134.76 & 316 & 2338003.31 \\
\hline RWM09 & 183997.00 & 5952302.95 & 12 & 2027805.09 \\
\hline RWM10 & 143777.00 & 869850.85 & 13 & 139220.43 \\
\hline RWM11 & 113579.00 & 2607773.84 & 18 & 857554.07 \\
\hline RWM12 & 84120.00 & 997663.20 & 14 & 275075.94 \\
\hline RWM13 & 124050.00 & 440377.50 & 3 & 200555.01 \\
\hline RWM14 & 89651.00 & 23302984.43 & 190 & 1187788.77 \\
\hline RWM15 & 222310.00 & 3545844.50 & 8 & 401480.33 \\
\hline RWM16 & 191559.00 & 2744082.68 & 25 & 855005.90 \\
\hline RWM17 & 130.08 & 435748.88 & 7 & 254982.78 \\
\hline RWM18 & 40443.00 & 8412144.00 & 76 & 656852.84 \\
\hline RWM19 & 36103.00 & 5767454.25 & 56 & 231243.55 \\
\hline RWM20 & 808.00 & 298960.00 & 11 & 309516.93 \\
\hline RWM21 & 44625.00 & 35469065.63 & 242 & 1131164.81 \\
\hline RWM22 & 47900.00 & 94602.50 & 1 & 159253.07 \\
\hline RWM23 & 39693.00 & 30173626.28 & 247 & 815449.04 \\
\hline RWM24 & 49022.00 & 145840.45 & 11 & 37032.69 \\
\hline RWM25 & 252.00 & 1008.00 & 1 & 924.00 \\
\hline RWM26 & 207.97 & 3161144.00 & 94 & 247542.09 \\
\hline RWM27 & 217.56 & 1740480.00 & 53 & 288733.95 \\
\hline RWM28 & 502.91 & 1282420.50 & 20 & 143704.58 \\
\hline RWM29 & 872.02 & 654015.00 & 14 & 188063.02 \\
\hline RWM30 & 249.17 & 2846767.25 & 45 & 105403.11 \\
\hline RWM31 & 150.54 & 4730719.50 & 160 & 544032.68 \\
\hline RWM32 & 929.20 & 3793322.41 & 82 & 426584.31 \\
\hline RWM33 & 541.86 & 7721505.00 & 47 & 2524225.50 \\
\hline RWM34 & 69.74 & 209220.00 & 62 & 84230.00 \\
\hline RWM35 & 16.73 & 47680.50 & 6 & 12657.06 \\
\hline RWM36 & 63.98 & 495205.20 & 18 & 132829.51 \\
\hline RWM37 & 78.09 & 80042.25 & 13 & 30178.76 \\
\hline RWM38 & 100.37 & 194717.80 & 32 & 32524.58 \\
\hline RWM39 & 192.19 & 2025682.60 & 100 & 517510.92 \\
\hline RWM40 & 3267.89 & 32456.68 & 2 & 51456.87 \\
\hline RWM41 & 725.67 & 1015938.00 & 13 & 993045.03 \\
\hline RWM42 & 193.40 & 527015.00 & 99 & 41008.86 \\
\hline RWM43 & 125.78 & 334574.80 & 53 & 49851.11 \\
\hline RWM44 & 187.96 & 2777109.00 & 107 & 88603.17 \\
\hline RWM45 & 270.75 & 5027827.50 & 127 & 215887.51 \\
\hline
\end{tabular}




\section{Appendix A}

Continued.

\begin{tabular}{|c|c|c|c|c|}
\hline Code No & Rate (INR) & $\begin{array}{c}\text { Annual Consumption Cost } \\
\text { (INR) }\end{array}$ & $\begin{array}{c}\text { Yearly Issue } \\
\text { (No. of issues/year) }\end{array}$ & Avg. Inventory cost (INR) \\
\hline RWM46 & 359.09 & 236999.40 & 25 & 62905.43 \\
\hline RWM47 & 269.34 & 211431.90 & 32 & 49864.78 \\
\hline RWM49 & 509.93 & 101986.00 & 3 & 15935.31 \\
\hline RWM50 & 145.13 & 1846779.25 & 168 & 106031.44 \\
\hline RWM51 & 393.48 & 5559872.40 & 180 & 304699.39 \\
\hline RWM53 & 258.55 & 12604312.50 & 247 & 308689.46 \\
\hline RWM54 & 315.03 & 190593.15 & 16 & 46707.10 \\
\hline RWM55 & 270.27 & 1724322.60 & 111 & 165419.86 \\
\hline RWM56 & 338.63 & 277676.60 & 14 & 38325.48 \\
\hline RWM57 & 149.88 & 3747000.00 & 152 & 175309.40 \\
\hline RWM58 & 245.00 & 2982875.00 & 183 & 199479.17 \\
\hline RWM59 & 65.14 & 141679.50 & 43 & 15349.32 \\
\hline RWM61 & 62.18 & 220739.00 & 31 & 83698.48 \\
\hline RWM62 & 144.63 & 2390010.75 & 169 & 150458.85 \\
\hline RWM63 & 129.42 & 6471.00 & 1 & 2084.00 \\
\hline RWM64 & 38.81 & 23286.00 & 3 & 21200.69 \\
\hline RWM65 & 5382.00 & 80536.25 & 6 & 127372.43 \\
\hline RWM66 & 32.03 & 2657417.00 & 54 & 280588.36 \\
\hline RWM67 & 23.15 & 7122190.10 & 140 & 221589.10 \\
\hline RWM68 & 71.42 & 89560.68 & 3 & 12017.50 \\
\hline RWM69 & 80.73 & 48438.00 & 3 & 68900.00 \\
\hline RWM70 & 248.55 & 1714995.00 & 10 & 2133363.99 \\
\hline RWM71 & 19.12 & 237604.24 & 97 & 44509.85 \\
\hline RWM72 & 78.66 & 35397.00 & 6 & 5875.00 \\
\hline RWM73 & 47.52 & 3219480.00 & 280 & 142053.33 \\
\hline RWM74 & 112.41 & 477742.50 & 60 & 79214.47 \\
\hline RWM75 & 36.57 & 12388087.50 & 202 & 628093.28 \\
\hline RWM78 & 1.85 & 63270.00 & 34 & 5647.50 \\
\hline RWM79 & 2.70 & 2160.00 & 3 & 1598.65 \\
\hline RWM80 & 9.06 & 1535488.80 & 141 & 43778.75 \\
\hline RWM81 & 22.29 & 8693856.43 & 146 & 307858.56 \\
\hline RWM82 & 318.76 & 14726712.00 & 176 & 1110382.43 \\
\hline RWM83 & 33.68 & 7350660.00 & 218 & 421987.78 \\
\hline RWM84 & 10.36 & 814296.00 & 214 & 44675.88 \\
\hline RWM85 & 111.25 & 2205531.25 & 145 & 201868.86 \\
\hline RWM86 & 100.09 & 16795102.00 & 313 & 739851.23 \\
\hline RWM87 & 107.03 & 774897.20 & 136 & 126856.74 \\
\hline RWM88 & 4.70 & 3760.00 & 8 & 1593.75 \\
\hline RWM89 & 40.74 & 65184.00 & 5 & 33000.39 \\
\hline RWM90 & 151.53 & 41670.75 & 5 & 2416.67 \\
\hline Weight & 0.105 & 0.395 & 0.314 & 0.187 \\
\hline
\end{tabular}




\section{Appendix B}

$\mathrm{R}$ programming for $\mathrm{ABC}$ classification by the modified similarity-based method

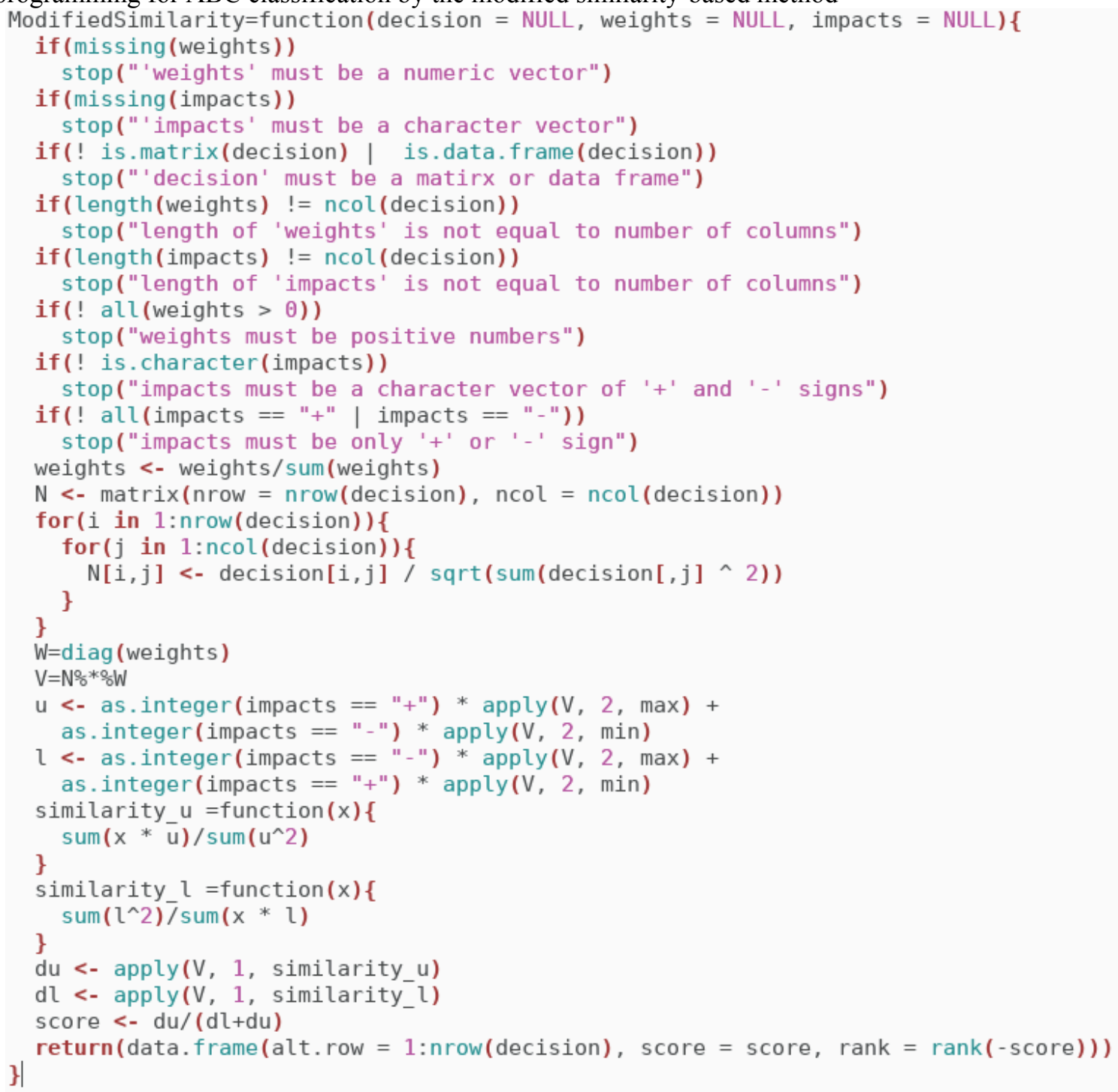


Appendix C

Comparison of ABC inventory classification by Modified Similarity-Based Method, TOPSIS, and AHP Modified similarity TOPSIS AHP

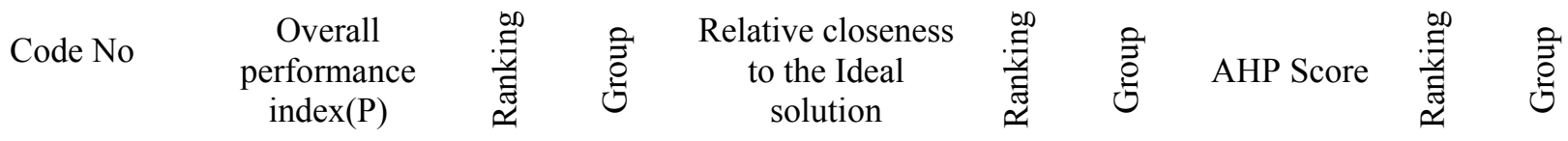

\begin{tabular}{|c|c|c|c|c|c|c|c|c|c|}
\hline RWM01 & 0.79639 & 29 & $\mathrm{C}$ & 0.10975 & 19 & B & 0.13103 & 28 & $\mathrm{C}$ \\
\hline RWM02 & 0.13716 & 61 & $\mathrm{C}$ & 0.04751 & 47 & $\mathrm{C}$ & 0.05860 & 48 & $\mathrm{C}$ \\
\hline RWM03 & 0.99677 & 1 & A & 0.72731 & 1 & A & 0.80062 & 1 & A \\
\hline RWM04 & 0.86626 & 23 & B & 0.09689 & 25 & $\mathrm{C}$ & 0.15351 & 23 & B \\
\hline RWM05 & 0.00891 & 75 & $\mathrm{C}$ & 0.01157 & 67 & $\mathrm{C}$ & 0.01439 & 70 & $\mathrm{C}$ \\
\hline RWM06 & 0.97449 & 6 & A & 0.21269 & 4 & A & 0.30420 & 6 & A \\
\hline RWM07 & 0.98929 & 2 & A & 0.44318 & 2 & A & 0.50944 & 2 & A \\
\hline RWM08 & 0.98690 & 3 & A & 0.27089 & 3 & A & 0.42809 & 3 & A \\
\hline RWM09 & 0.37590 & 48 & $\mathrm{C}$ & 0.09549 & 27 & $\mathrm{C}$ & 0.11992 & 34 & $\mathrm{C}$ \\
\hline RWM10 & 0.15973 & 54 & $\mathrm{C}$ & 0.06988 & 35 & $\mathrm{C}$ & 0.08192 & 43 & $\mathrm{C}$ \\
\hline RWM11 & 0.30531 & 50 & $\mathrm{C}$ & 0.05894 & 44 & $\mathrm{C}$ & 0.07930 & 45 & $\mathrm{C}$ \\
\hline RWM12 & 0.14813 & 59 & $\mathrm{C}$ & 0.04288 & 49 & $\mathrm{C}$ & 0.05561 & 50 & $\mathrm{C}$ \\
\hline RWM13 & 0.03257 & 70 & $\mathrm{C}$ & 0.06036 & 41 & $\mathrm{C}$ & 0.06314 & 47 & $\mathrm{C}$ \\
\hline RWM14 & 0.96064 & 8 & A & 0.15925 & 9 & A & 0.26462 & 9 & A \\
\hline RWM15 & 0.20239 & 52 & $\mathrm{C}$ & 0.10554 & 21 & B & 0.12125 & 33 & $\mathrm{C}$ \\
\hline RWM16 & 0.43307 & 45 & $\mathrm{C}$ & 0.09363 & 28 & $\mathrm{C}$ & 0.12261 & 32 & C \\
\hline RWM17 & 0.02797 & 72 & $\mathrm{C}$ & 0.00531 & 74 & $\mathrm{C}$ & 0.00849 & 75 & C \\
\hline RWM18 & 0.78900 & 31 & $\mathrm{C}$ & 0.06381 & 38 & $\mathrm{C}$ & 0.10712 & 35 & $\mathrm{C}$ \\
\hline RWM19 & 0.65273 & 39 & $\mathrm{C}$ & 0.04683 & 48 & $\mathrm{C}$ & 0.07974 & 44 & $\mathrm{C}$ \\
\hline RWM20 & 0.04724 & 68 & $\mathrm{C}$ & 0.00759 & 73 & $\mathrm{C}$ & 0.01238 & 72 & $\mathrm{C}$ \\
\hline RWM21 & 0.97749 & 4 & A & 0.21037 & 5 & A & 0.31387 & 5 & A \\
\hline RWM22 & 0.00460 & 79 & $\mathrm{C}$ & 0.02414 & 59 & $\mathrm{C}$ & 0.02451 & 62 & C \\
\hline RWM23 & 0.97499 & 5 & A & 0.19600 & 6 & A & 0.30374 & 7 & A \\
\hline RWM24 & 0.05484 & 66 & $\mathrm{C}$ & 0.02543 & 58 & $\mathrm{C}$ & 0.03343 & 57 & $\mathrm{C}$ \\
\hline RWM25 & 0.00017 & 90 & $\mathrm{C}$ & 0.00013 & 89 & $\mathrm{C}$ & 0.00102 & 89 & $\mathrm{C}$ \\
\hline RWM26 & 0.71885 & 35 & $\mathrm{C}$ & 0.05975 & 42 & $\mathrm{C}$ & 0.09153 & 39 & $\mathrm{C}$ \\
\hline RWM27 & 0.45890 & 43 & $\mathrm{C}$ & 0.03407 & 53 & $\mathrm{C}$ & 0.05233 & 53 & C \\
\hline RWM28 & 0.14719 & 60 & $\mathrm{C}$ & 0.01358 & 66 & $\mathrm{C}$ & 0.02138 & 65 & $\mathrm{C}$ \\
\hline RWM29 & 0.07305 & 65 & $\mathrm{C}$ & 0.00916 & 70 & $\mathrm{C}$ & 0.01517 & 68 & C \\
\hline RWM30 & 0.44770 & 44 & $\mathrm{C}$ & 0.03073 & 55 & $\mathrm{C}$ & 0.04650 & 55 & $\mathrm{C}$ \\
\hline RWM31 & 0.87684 & 21 & B & 0.09883 & 24 & B & 0.15502 & 21 & B \\
\hline RWM32 & 0.70292 & 38 & $\mathrm{C}$ & 0.05382 & 46 & $\mathrm{C}$ & 0.08336 & 42 & C \\
\hline RWM33 & 0.70496 & 37 & $\mathrm{C}$ & 0.05424 & 45 & $\mathrm{C}$ & 0.07063 & 46 & C \\
\hline RWM34 & 0.39239 & 47 & $\mathrm{C}$ & 0.03841 & 50 & $\mathrm{C}$ & 0.05616 & 49 & $\mathrm{C}$ \\
\hline RWM35 & 0.00677 & 76 & $\mathrm{C}$ & 0.00324 & 77 & $\mathrm{C}$ & 0.00552 & 77 & $\mathrm{C}$ \\
\hline RWM36 & 0.08651 & 64 & $\mathrm{C}$ & 0.01127 & 68 & $\mathrm{C}$ & 0.01776 & 67 & $\mathrm{C}$ \\
\hline RWM37 & 0.03016 & 71 & $\mathrm{C}$ & 0.00775 & 72 & $\mathrm{C}$ & 0.01194 & 73 & C \\
\hline RWM38 & 0.15306 & 57 & $\mathrm{C}$ & 0.01982 & 62 & $\mathrm{C}$ & 0.02914 & 60 & $\mathrm{C}$ \\
\hline RWM39 & 0.71642 & 36 & $\mathrm{C}$ & 0.06247 & 39 & $\mathrm{C}$ & 0.09597 & 38 & C \\
\hline RWM40 & 0.00179 & 87 & $\mathrm{C}$ & 0.00190 & 83 & $\mathrm{C}$ & 0.00366 & 81 & C \\
\hline RWM41 & 0.12944 & 62 & $\mathrm{C}$ & 0.01497 & 65 & $\mathrm{C}$ & 0.01907 & 66 & C \\
\hline RWM42 & 0.62531 & 40 & $\mathrm{C}$ & 0.06062 & 40 & $\mathrm{C}$ & 0.08963 & 40 & C \\
\hline RWM43 & 0.33195 & 49 & $\mathrm{C}$ & 0.03292 & 54 & $\mathrm{C}$ & 0.04824 & 54 & C \\
\hline RWM44 & 0.74142 & 33 & $\mathrm{C}$ & 0.06676 & 37 & $\mathrm{C}$ & 0.10152 & 37 & $\mathrm{C}$ \\
\hline RWM45 & 0.83189 & 27 & $\mathrm{C}$ & 0.08069 & 34 & $\mathrm{C}$ & 0.12456 & 30 & C \\
\hline
\end{tabular}




\section{Appendix C}

Continued.

\begin{tabular}{|c|c|c|c|c|c|c|c|c|c|}
\hline \multirow[b]{2}{*}{ Code No } & \multicolumn{3}{|c|}{ Modified similarity } & \multicolumn{3}{|c|}{ TOPSIS } & \multicolumn{3}{|c|}{ AHP } \\
\hline & $\begin{array}{c}\text { Overall } \\
\text { performance } \\
\text { index }(\mathrm{P})\end{array}$ & 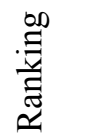 & $\begin{array}{l}O \\
0 \\
0\end{array}$ & $\begin{array}{l}\text { Relative closeness } \\
\text { to the Ideal } \\
\text { solution }\end{array}$ & $\frac{\infty}{\stackrel{\Xi}{\Xi}}$ & 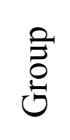 & AHP Score & $\frac{\infty}{\stackrel{\Xi}{\Xi}}$ & Oे \\
\hline RWM46 & 0.11018 & 63 & $\mathrm{C}$ & 0.01544 & 64 & $\mathrm{C}$ & 0.02326 & 64 & $\mathrm{C}$ \\
\hline RWM47 & 0.15688 & 55 & $\mathrm{C}$ & 0.01984 & 61 & $\mathrm{C}$ & 0.02934 & 59 & $\mathrm{C}$ \\
\hline RWM48 & 0.00346 & 81 & $\mathrm{C}$ & 0.00193 & 82 & $\mathrm{C}$ & 0.00333 & 82 & $\mathrm{C}$ \\
\hline RWM49 & 0.00283 & 83 & $\mathrm{C}$ & 0.00141 & 85 & $\mathrm{C}$ & 0.00320 & 83 & $\mathrm{C}$ \\
\hline RWM50 & 0.84475 & 26 & $\mathrm{C}$ & 0.10035 & 23 & B & 0.15411 & 22 & $\mathrm{~B}$ \\
\hline RWM51 & 0.89871 & 16 & B & 0.11027 & 18 & $\mathrm{~B}$ & 0.17340 & 18 & $\mathrm{~B}$ \\
\hline RWM52 & 0.90108 & 15 & B & 0.12268 & 16 & B & 0.19297 & 14 & $\mathrm{~B}$ \\
\hline RWM53 & 0.95497 & 9 & A & 0.15417 & 11 & A & 0.24724 & 11 & A \\
\hline RWM54 & 0.05097 & 67 & $\mathrm{C}$ & 0.00971 & 69 & $\mathrm{C}$ & 0.01504 & 69 & $\mathrm{C}$ \\
\hline RWM55 & 0.72568 & 34 & $\mathrm{C}$ & 0.06829 & 36 & $\mathrm{C}$ & 0.10340 & 36 & $\mathrm{C}$ \\
\hline RWM56 & 0.04475 & 69 & $\mathrm{C}$ & 0.00848 & 71 & $\mathrm{C}$ & 0.01340 & 71 & $\mathrm{C}$ \\
\hline RWM57 & 0.85102 & 25 & $\mathrm{C}$ & 0.09310 & 29 & $\mathrm{C}$ & 0.14402 & 25 & $\mathrm{C}$ \\
\hline RWM58 & 0.87823 & 19 & B & 0.10932 & 20 & B & 0.17029 & 19 & B \\
\hline RWM59 & 0.23081 & 51 & $\mathrm{C}$ & 0.02668 & 57 & $\mathrm{C}$ & 0.03873 & 56 & $\mathrm{C}$ \\
\hline RWM60 & 0.87775 & 20 & B & 0.11208 & 17 & B & 0.17428 & 17 & B \\
\hline RWM61 & 0.15404 & 56 & $\mathrm{C}$ & 0.01923 & 63 & $\mathrm{C}$ & 0.02854 & 61 & $\mathrm{C}$ \\
\hline RWM62 & 0.85478 & 24 & B & 0.10128 & 22 & B & 0.15632 & 20 & B \\
\hline RWM63 & 0.00019 & 89 & $\mathrm{C}$ & 0.00007 & 90 & $\mathrm{C}$ & 0.00098 & 90 & $\mathrm{C}$ \\
\hline RWM64 & 0.00194 & 86 & $\mathrm{C}$ & 0.00132 & 87 & $\mathrm{C}$ & 0.00285 & 87 & $\mathrm{C}$ \\
\hline RWM65 & 0.01307 & 73 & $\mathrm{C}$ & 0.00453 & 75 & $\mathrm{C}$ & 0.00871 & 74 & C \\
\hline RWM66 & 0.51381 & 42 & $\mathrm{C}$ & 0.03580 & 52 & $\mathrm{C}$ & 0.05494 & 51 & C \\
\hline RWM67 & 0.87239 & 22 & B & 0.09081 & 30 & $\mathrm{C}$ & 0.14027 & 26 & C \\
\hline RWM68 & 0.00255 & 85 & $\mathrm{C}$ & 0.00136 & 86 & $\mathrm{C}$ & 0.00295 & 86 & C \\
\hline RWM69 & 0.00302 & 82 & $\mathrm{C}$ & 0.00155 & 84 & $\mathrm{C}$ & 0.00316 & 84 & C \\
\hline RWM70 & 0.17289 & 53 & $\mathrm{C}$ & 0.02739 & 56 & $\mathrm{C}$ & 0.02343 & 63 & $\mathrm{C}$ \\
\hline RWM71 & 0.60023 & 41 & $\mathrm{C}$ & 0.05935 & 43 & $\mathrm{C}$ & 0.08720 & 41 & $\mathrm{C}$ \\
\hline RWM72 & 0.00630 & 77 & $\mathrm{C}$ & 0.00324 & 78 & $\mathrm{C}$ & 0.00549 & 78 & $\mathrm{C}$ \\
\hline RWM73 & 0.93830 & 13 & B & 0.15871 & 10 & A & 0.25686 & 10 & A \\
\hline RWM74 & 0.39996 & 46 & $\mathrm{C}$ & 0.03727 & 51 & $\mathrm{C}$ & 0.05491 & 52 & $\mathrm{C}$ \\
\hline RWM75 & 0.94184 & 10 & A & 0.13222 & 13 & B & 0.20822 & 13 & B \\
\hline RWM76 & 0.94087 & 11 & A & 0.16737 & 8 & A & 0.27233 & 8 & A \\
\hline RWM77 & 0.00279 & 84 & $\mathrm{C}$ & 0.00215 & 81 & $\mathrm{C}$ & 0.00308 & 85 & $\mathrm{C}$ \\
\hline RWM78 & 0.15258 & 58 & $\mathrm{C}$ & 0.02105 & 60 & $\mathrm{C}$ & 0.03047 & 58 & $\mathrm{C}$ \\
\hline RWM79 & 0.00138 & 88 & $\mathrm{C}$ & 0.00130 & 88 & $\mathrm{C}$ & 0.00269 & 88 & $\mathrm{C}$ \\
\hline RWM80 & 0.79121 & 30 & $\mathrm{C}$ & 0.08520 & 32 & $\mathrm{C}$ & 0.12902 & 29 & $\mathrm{C}$ \\
\hline RWM81 & 0.89128 & 17 & B & 0.09670 & 26 & $\mathrm{C}$ & 0.14922 & 24 & B \\
\hline RWM82 & 0.93931 & 12 & B & 0.12504 & 14 & B & 0.19235 & 16 & B \\
\hline RWM83 & 0.93142 & 14 & B & 0.13230 & 12 & B & 0.21131 & 12 & B \\
\hline RWM84 & 0.88207 & 18 & B & 0.12415 & 15 & B & 0.19267 & 15 & B \\
\hline RWM85 & 0.81736 & 28 & $\mathrm{C}$ & 0.08796 & 31 & $\mathrm{C}$ & 0.13480 & 27 & $\mathrm{C}$ \\
\hline RWM86 & 0.97270 & 7 & A & 0.19217 & 7 & A & 0.31664 & 4 & A \\
\hline RWM87 & 0.76339 & 32 & $\mathrm{C}$ & 0.08204 & 33 & $\mathrm{C}$ & 0.12351 & 31 & $\mathrm{C}$ \\
\hline RWM88 & 0.00955 & 74 & $\mathrm{C}$ & 0.00452 & 76 & $\mathrm{C}$ & 0.00715 & 76 & $\mathrm{C}$ \\
\hline RWM89 & 0.00580 & 78 & $\mathrm{C}$ & 0.00263 & 79 & $\mathrm{C}$ & 0.00478 & 79 & $\mathrm{C}$ \\
\hline RWM90 & 0.00457 & 80 & $\mathrm{C}$ & 0.00260 & 80 & $\mathrm{C}$ & 0.00463 & 80 & $\mathrm{C}$ \\
\hline
\end{tabular}




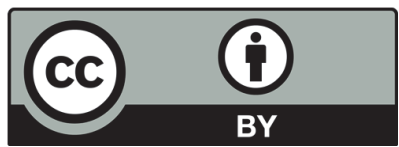

(C) 2019 by the authors; licensee Growing Science, Canada. This is an open access article distributed under the terms and conditions of the Creative Commons Attribution (CC-BY) license (http://creativecommons.org/licenses/by/4.0/). 